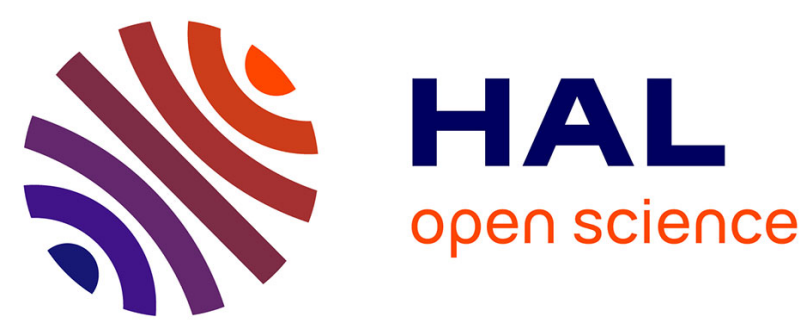

\title{
Age trends of microfibril angle inheritance and their genetic and environmental correlations with growth, density and chemical properties in Eucalyptus urophylla ST Blake wood
}

Paulo Ricardo Gherardi Hein, Jean-Marc Bouvet, Eric Mandrou, Philippe

Vigneron, Bruno Clair, Gilles Chaix

\section{To cite this version:}

Paulo Ricardo Gherardi Hein, Jean-Marc Bouvet, Eric Mandrou, Philippe Vigneron, Bruno Clair, et al. Age trends of microfibril angle inheritance and their genetic and environmental correlations with growth, density and chemical properties in Eucalyptus urophylla ST Blake wood. Annals of Forest Science, 2012, 69 (6), pp.681 - 691. 10.1007/s13595-012-0186-3 . hal-02644062

\author{
HAL Id: hal-02644062 \\ https://hal.inrae.fr/hal-02644062
}

Submitted on 28 May 2020

HAL is a multi-disciplinary open access archive for the deposit and dissemination of scientific research documents, whether they are published or not. The documents may come from teaching and research institutions in France or abroad, or from public or private research centers.
L'archive ouverte pluridisciplinaire HAL, est destinée au dépôt et à la diffusion de documents scientifiques de niveau recherche, publiés ou non, émanant des établissements d'enseignement et de recherche français ou étrangers, des laboratoires publics ou privés.

$$
\text { Copyright }
$$




\title{
Age trends of microfibril angle inheritance and their genetic and environmental correlations with growth, density and chemical properties in Eucalyptus urophylla S.T. Blake wood
}

\author{
Paulo Ricardo Gherardi Hein • Jean-Marc Bouvet • \\ Eric Mandrou • Philippe Vigneron • Bruno Clair • \\ Gilles Chaix
}

Received: 21 April 2011 / Accepted: 20 January 2012 / Published online: 24 February 2012

(C) INRA / Springer-Verlag France 2012

\begin{abstract}
- Context The genetic and environmental control of microfibril angle (MFA) and its genetic correlations with other wood and growth traits are still not well established in Eucalyptus sp.

Handling Editor: Barry Alan Gardiner

Contribution of the co-authors PRGH was responsible for performing the near infrared (NIR), X-ray diffraction analysis and wood measurements, for generating the phenotypic data set, analysing the results and the writing of the paper. This study is a part of his $\mathrm{PhD}$ thesis;

JMB was responsible for planning the experimental design and performing the statistical and all the genetic analysis. He co-writes the paper with PRGH.

EM wrote part of the Material and methods section.

PV was responsible for planning the experimental design and part of the preliminary analysis.

$\mathrm{BC}$ was responsible for performing the $\mathrm{X}$-ray difractometry analysis at Univ. of Montpellier 2. He gave valuable insights to the study and he help to improve part of the discussions.

$\mathrm{GC}$ was responsible for planning the measurements and analysing the results. He's co-supervisor of PRGH PhD. He provides comments and corrections to the text.
\end{abstract}

\section{P. R. G. Hein}

CIRAD, UPR Bois Tropicaux,

34398 F- Montpellier, France

P. R. G. Hein · B. Clair

Laboratoire de Mécanique et Génie Civil (LMGC),

CNRS, Université Montpellier 2,

Place E. Bataillon, cc48,

34095 Montpellier, France

e-mail: bruno.clair@univ-montp2.fr

P. R. G. Hein $(\bowtie)$

Universidade Federal de Lavras, DCF-UFLA,

Minas Gerais, Brazil

e-mail: phein1980@gmail.com
- Aims To determine the narrow-sense heritability estimates $\left(h^{2}\right)$ of MFA, wood density (D), Klason lignin (KL) content, syringyl to guaiacyl $(\mathrm{S} / \mathrm{G})$ ratio and growth traits, their variation from pith to cambium and their genetic correlations.
J.-M. Bouvet $\cdot$ E. Mandrou $\cdot$ P. Vigneron $\cdot$ G. Chaix

CIRAD, UMR AGAP,

34398 F- Montpellier, France

J.-M. Bouvet

e-mail: jean-marc.bouvet@cirad.fr

P. Vigneron

e-mail: philippe.vigneron@cirad.fr

G. Chaix

e-mail: gilles.chaix@cirad.fr 
- Methods Heritability and correlations were assessed in 340 control-pollinated progenies of 14-year-Eucalyptus urophylla S.T. Blake using near infrared spectroscopic models. - Results Moderate to high heritability were found for MFA $\left(h^{2}=0.43\right), \mathrm{D}\left(h^{2}=0.61\right), \mathrm{S} / \mathrm{G}\left(h^{2}=0.71\right)$ and LK $\left(h^{2}=0.76\right)$. The genetic control of D and MFA and the genetic and residual correlation between chemical and growth traits varied with age. The genetic correlation $\mathrm{C} \times \mathrm{D}$ was always strongly negative $(r<-0.80)$ while the correlation $\mathrm{D} \times$ MFA remained constant and positive in the juvenile wood $(r=0.7)$, before disappearing in the mature wood. These results could be explained by gene pleiotropic effect, low microfibril angle compensating for low wood density and fast growth or by linkage disequilibrium induced by sampling. Variations in MFA and KL in the mature wood were also genetically controlled.

- Conclusions These findings provide the opportunity for developing breeding strategies for pulpwood, fuelwood and sawntimber production in Eucalyptus sp.

Keywords Variance components · MFA · Klason lignin . Syringyl to guaiacyl ratio $\cdot$ Factorial mating design $\cdot$ Wood phenotyping $\cdot$ NIR spectroscopy

\section{Introduction}

Eucalyptus is one of the most widely cultivated hardwood genera in tropical and subtropical regions of the world. This genus is adapted to a variety of climatic and edaphic conditions and grows at high rates producing raw material adequate for many end uses. Wood quality is determined from the combination of intrinsic factors such as stiffness that depend on microfibril angle (MFA), density and the chemical contents of its main components (Kollmann and Coté 1968). A range of studies have pointed out the importance of microfibril angle for the wood stiffness and wood products quality in Eucalyptus sp (Evans and Ilic 2001). In general, wood in which the MFA is low has high rigidity and high economic value. Hence, the determination of the genetic factors contributing to quantitative trait variation of wood properties is essential for

\footnotetext{
E. Mandrou

Centre de recherche Vallourec, $\mathrm{CEV}$,

Route de Leval BP 17,

Aulnoye Aymeries, France

E. Mandrou

INRA, UMR 1202 BIOGECO,

69 route d'Arcachon,

Cestas, Pierroton, France

P. Vigneron

CRDPI,

BP 1291,

Pointe Noire, Republic of Congo
}

tree breeders (Raymond 2002; Apiolaza 2009) allowing the selection of trees with adequate characteristics for the proposed end use. Furthermore, adverse genetic and environmental correlations between wood quality and growth traits remain as one of the main constraints in tree breeding programmes for pulp and paper, bio-energy or sawnwood industries.

Growth, cellulose content, and wood density (or pilodyn penetration, which is an indirect method for determining wood density; see Raymond and MacDonald (1998) are the main traits considered by tree breeders for Eucalyptus pulpwood plantations and many papers have reported heritability estimates and correlations among these properties (Greaves et al. 1997; Raymond 2002; Costa e Silva et al. 2009). However, the genetic parameters of chemical, mechanical and ultrastructural features are rarely reported in Eucalyptus. Moreover, the estimation of genetic parameters of these wood traits presents a large variation according to the peculiarities of each study. For instance, the findings reported by Kube et al. (2001) in Eucalyptus nitens and Apiolaza et al. (2005) and Poke et al. (2006) in Eucalyptus globulus are contrasting, demonstrating that heritability estimates and genetic correlations are specific to the population and site under investigation, but also that they have to be considered with caution due to the low accuracy of their estimation.

With the growing need and interest in establishing plantations for producing stiff and dimensionally stable wood with minimal growth stresses, recent studies have focused on the heritability of traits controlling wood quality (Baltunis et al. 2007). Most of the studies dealing with the genetic control of MFA have been carried out on softwoods because of the generally low stiffness and poor dimensional stability of the juvenile wood. In hardwoods, the degree to which MFA is heritable and its genetic relationship with other traits has not often been reported, especially for Eucalyptus wood. To our knowledge, there is only one study reporting narrowsense heritability estimates ( $h^{2}$; Apiolaza et al. 2005) and another study providing broad-sense heritability estimates $\left(H^{2}\right)$ for MFA in Eucalyptus (Lima et al. 2004). References reporting genetic and environmental correlations among MFA, density, lignin, syringyl to guaiacyl ratio and growth traits are rare in Eucalyptus. The extent to which microfibril angle is controlled by additive genetic and environmental factors is poorly documented; and the relationship between MFA and the other wood and growth traits, and how these relationships vary with age are still not established in Eucalyptus. Knowledge about these issues would be useful to understand how trees adapt their wood traits in order to maintain their erect habit even when they are subjected to bending movements in response to wind and gravity.

Therefore, the main aims of this study were: (1) to assess the level of genetic control of MFA, wood density (D), Klason lignin content $(\mathrm{KL})$, and syringyl to guaiacyl ratio $(\mathrm{S} / \mathrm{G})$ and growth traits from a 14-year-old control-pollinated progeny 
test of Eucalyptus urophylla; (2) to determine the genetic and residual correlations among MFA, D, KL, S/G and growth traits; and (3) to investigate the age trends of these genetic parameters.

Most studies on genetic parameters of Eucalyptus wood traits have been based on averaged values per tree. Because MFA and wood density vary greatly from pith to cambium (Kollmann and Coté 1968) assessing averaged values may not be the best option. In this study, MFA and wood density were assessed in three radial positions namely early juvenile wood, late juvenile wood and early mature wood. Radial variation of genetic parameters and the genetic and residual correlations among these wood traits are presented and the implications for selection are discussed.

\section{Material and methods}

\subsection{Genetic material}

Three hundred and forty wood discs were collected at breast height from a 14-year-old E. urophylla S.T. Blake progeny trial stand in Pointe Noire, Republic of Congo, in the experimental area of the "Centre de Recherche sur la Durabilité et la Productivité des Plantations Industrielles-CRDPI" $\left(04^{\circ} 45^{\prime} \mathrm{S}, 12^{\circ}\right.$ $00^{\prime} \mathrm{E}$; altitude, $50 \mathrm{~m}$ ). The climate is tropical humid with a mean annual temperature of $24^{\circ} \mathrm{C}$, a mean annual rainfall of $1,200 \mathrm{~mm}$ and a dry season from May to October. This progeny trial was established in 1992. It was composed of 33 full-sib families produced by controlled pollination using an incomplete factorial mating design (ratio 33/64) involving 16 parents (eight males and eight females) originally from two provenances (eight from Mont Egon and eight from Mont Lewotobi of the Flores Island in the Sunda Archipelago, $122-127^{\circ} \mathrm{E}$, $8-10^{\circ} \mathrm{S}$ ). In 2006 , nine to ten trees from each family were selected with the best growth and stem straightness and harvested, resulting in a total of 340 sample trees. Trees were collected from only one block to limit the impact of destructive sampling in the entire trial. This solution did not affect the genetic analysis capacity as the number of trees sampled was high and the harvested block presented very homogenous soil conditions. The circumference at breast height (C) and the height $(\mathrm{H})$ of the trees were measured at 14 years, immediately before harvesting. After harvesting, discs of wood ( $\sim 30 \mathrm{~mm}$ thick) were obtained at breast height of each tree and transported to "Centre de Coopération Internationale en Recherche Agronomique pour le Développement" (CIRAD) in Montpellier, France where the analyses were performed.

\subsection{Sample preparation}

Defect-free wedges were cut from the discs and milled using a knife mill (Retsch GmbH, Haan, Germany; model SM100) and an ultracentrifugal mill (Retsch GmbH, Haan, Germany; model ZM 200) in order to produce grounded wood (particle sizes lower than $0.5 \mathrm{~mm}$ ) for wet-chemistry analysis (Fig. 1, sample a). Pith to bark radial strips (defects free) were removed from the discs using vertical bandsaw machine at random azimuthal directions. Then, small wood samples

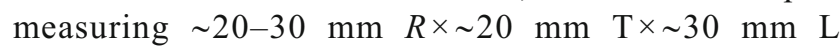
(Fig. 1, sample b) and tangential sections (Fig. 1, sample c) measuring $\sim 2 \mathrm{~mm} R \times \sim 20 \mathrm{~mm} \mathrm{~T} \times \sim 30 \mathrm{~mm} \mathrm{~L}$ were cut, parallel to the growth rings, from each wood strip, for wood density and microfibril angle measurements, respectively. The wood powders of 60 samples were subjected to chemical analysis. In order to select 60 samples from the total sampling, principal component analysis of the NIR spectra was performed using the Unscrambler (CAMO AS, Norway) software version 9.7. Samples well representative in terms of NIR spectra were selected according to their Mahalanobis distances. The samples (milled and solid woods) were kept in a conditioned room at $50 \%$ relative humidity and temperature of $20^{\circ} \mathrm{C}$ before analysis. Under these conditions, the equilibrium moisture content was around $10 \%$.

\subsection{Wood phenotyping}

The KL content and ratio between syringyl (S) and guaiacyl (G) of the wood were determined by the Biological Chemistry Laboratory (INRA-Agro ParisTech, France). The analyses were performed in duplicate for the 60 samples and were previously reported in Hein et al. (2010a). The basic D was determined according to water immersion procedure in 190 small wood samples $(\sim 20 \times 25 \times 30 \mathrm{~mm})$ cut from radial strips as previously reported in Hein et al. (2009). All X-ray diffraction data were collected on a diffractometer (Xcalibur-I, Oxford Instruments, USA) with $\mathrm{CuK} \alpha$ radiation at "Institut Européen des Membranes" of the University of Montpellier, France. Three X-ray diffraction profiles were recorded and averaged for 175 tangential sections $(2 \times 20 \times$ $30 \mathrm{~mm}$ ) cut from radial strips. The error of the measure was estimated at 3\%. The procedure for microfibril angle measurements was previously reported in Hein et al. (2010b).

\subsection{Near-infrared spectroscopy analysis}

The wood traits under investigation in this study were based on predictions from NIR spectroscopy calibrations. NIR spectra were recorded using a spectrophotometer (model Vector 22/N, Bruker Optik GmbH, Ettlingen, Germany) on both milled and solid woods. First, NIR spectra were recorded on the radial surface of the wedges (NIR spectra 1 ) at three radial positions $(1,2$, and 3$)$ from pith to bark and on the wood powders (NIR spectra 2) and, for predictions (Fig. 1, sample a). 
Fig. 1 Procedure of sample preparation for wood characterization. Wedges $(A)$ and radial strips were cut from discs; small wood samples $(B)$ and tangential sections $(C)$ were cut for density and microfibril angle measurements. Nearinfrared (NIR) spectra 1, 3 and 4 were recorded from the early juvenile wood, late juvenile wood and early mature wood. The wedges were ground for wet-chemistry analysis and NIR spectra were measured from the powders (NIR spectra 2)
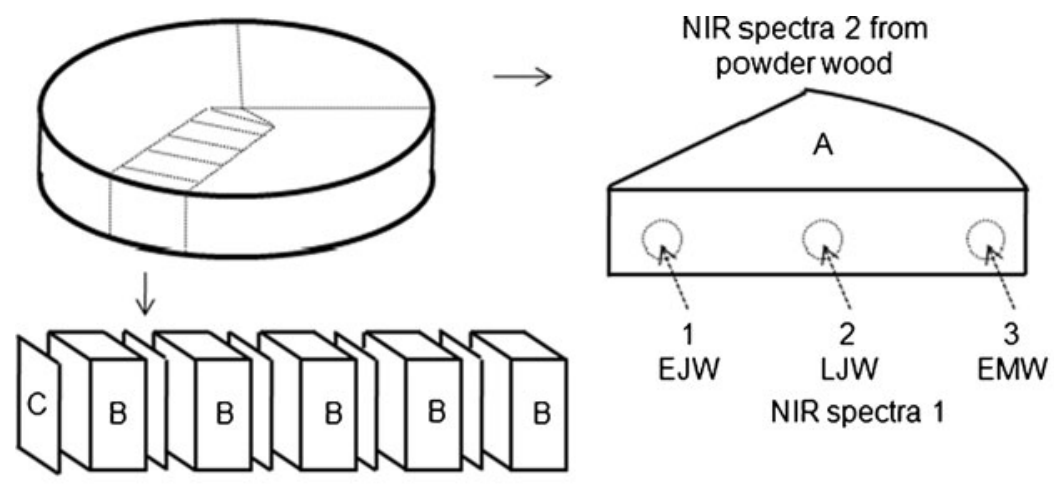

Small wood sample for density

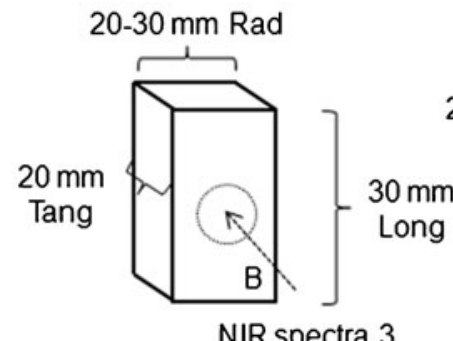

NIR spectra 3
Tangential section for MFA

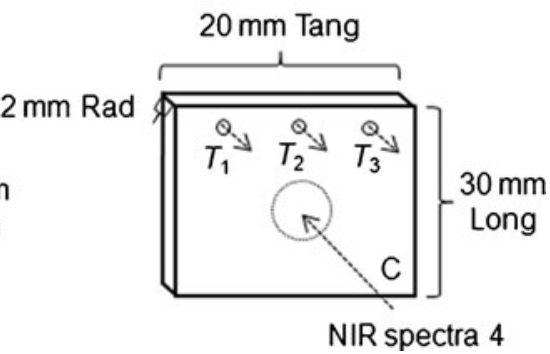

Point 1 represented the wood formed at $\sim 3-4$ years (hereafter called early juvenile wood; point 2 , the wood of the $\sim 6-$ 7 years (late juvenile wood); and point 3 , the wood of the $\sim 12$ 14 years (early mature wood). The averaged value per tree for density and microfibril angle are expressed as D and MFA, respectively, while the local D and MFA estimates are expressed as $D_{1}, D_{2}$, and $D_{3}$ and $\mathrm{MFA}_{1}, \mathrm{MFA}_{2}$, and MFA accordingly. A single, averaged value per tree was used for the chemical properties. We considered as outliers the samples

Table 1 Mean, minimum and maximum values, coefficient of variation $(\mathrm{CV})$ and number of observations $(\mathrm{N})$ for growth (circumference, $\mathrm{C}$ and height, $\mathrm{H}$ ), chemical properties (Klason lignin, KL and syringyl to guaiacyl ratio, $\mathrm{S} / \mathrm{G}$ ), wood density (D) and microfibril angle (MFA) of the 14-year-old E. urophylla population

\begin{tabular}{llllllr}
\hline Trait & Unit & $\mathrm{N}$ & Mean & Minimum & Maximum & $\begin{array}{l}\mathrm{CV}_{\mathrm{P}} \\
(\%)\end{array}$ \\
\hline $\mathrm{C}$ & $\mathrm{cm}$ & 340 & 52.7 & 24.0 & 84.0 & 21.2 \\
$\mathrm{H}$ & $\mathrm{m}$ & 340 & 21.2 & 7.8 & 29.6 & 17.3 \\
$\mathrm{KL}$ & $\%$ & 321 & 28.0 & 25.1 & 31.7 & 4.4 \\
$\mathrm{~S} / \mathrm{G}$ & - & 321 & 2.3 & 1.5 & 3.5 & 13.5 \\
$\mathrm{D}_{1}$ & $\mathrm{~kg} \mathrm{~m}^{-3}$ & 274 & 443 & 330 & 607 & 10.2 \\
$\mathrm{D}_{2}$ & $\mathrm{~kg} \mathrm{~m}^{-3}$ & 274 & 522 & 391 & 698 & 8.4 \\
$\mathrm{D}_{3}$ & $\mathrm{~kg} \mathrm{~m}^{-3}$ & 274 & 615 & 480 & 761 & 8.1 \\
$\mathrm{D}$ & $\mathrm{kg} \mathrm{m}^{-3}$ & 274 & 526 & 423 & 654 & 7.2 \\
$\mathrm{MFA}_{1}$ & Degrees & 274 & 18.1 & 12.7 & 23.9 & 10.2 \\
MFA $_{2}$ & Degrees & 274 & 15.3 & 10.0 & 21.1 & 12.4 \\
MFA $_{3}$ & Degrees & 274 & 13.3 & 7.2 & 19.5 & 13.9 \\
MFA & Degrees & 274 & 15.6 & 11.0 & 20.0 & 9.8 \\
\hline
\end{tabular}

which presented estimates with high standard errors, and removed them from the original dataset (Table 1).

Partial least square regressions (PLS-R) were developed from the NIR spectra of the wood powders and the chemical analysis of the 60 samples for KL and S/G ratio. These PLS-R calibrations were previously described in Hein et al. (2010a) providing the estimates of single values of KL content and $\mathrm{S}$ to $G$ ratio using the NIR spectra 2 taken from the grounded wood of the 340 discs. The PLS-R model for D was based on 190 small wood samples and their NIR spectra 3 (Hein et al. 2009) while the PLS-R model for MFA was based on 175 tangential sections and their NIR spectra 4 (Hein et al. 2010b). These established PLS-R models were applied on the NIR spectra 1 providing the estimates of MFA and wood density in the early and late juvenile wood and in the early mature wood. Table 2 presents fit statistics for the NIR-based models used for phenotyping the woods from this progeny trial.

\subsection{Statistical methods for genetic parameter estimation}

C, H, KL, S/G, D and MFA were analysed independently to estimate the variance components by using the following mixed linear model:

$y=X b+Z Q g+Z a+e$

where, $y$ is the vector of observations; $b$ is the vector of fixed effects (in our case the mean value of the trait in the population); $g$ is the vector of fixed effects related to parent groups; $a$ is the vector of genetic effects (individual additive genetic values), $e$ is the vector of residuals; and $X, Q$ and $Z$ 
Table 2 Partial least square regression models for estimating the microfibril angle (MFA), wood density (D), Klason lignin (KL) content and syringyl to guaiacyl ratio $(\mathrm{S} / \mathrm{G})$ from NIR spectra of $E$. urophylla wood

\begin{tabular}{lccccc}
\hline Trait & $\mathrm{R}^{2}{ }_{\mathrm{c}}$ & $\mathrm{RMSEC}$ & $R_{p}^{2}$ & $\mathrm{RMSECV}$ & $\mathrm{RPD}$ \\
\hline MFA (degrees) & 0.72 & 0.73 & 0.64 & 0.84 & 1.76 \\
$\mathrm{D}\left(\mathrm{kg} \mathrm{m}^{-3}\right)$ & 0.89 & 27.0 & 0.85 & 30.0 & 2.70 \\
KL $(\%)$ & 0.88 & 0.44 & 0.85 & 0.55 & 2.58 \\
S to G ratio (S/G) & 0.92 & 0.01 & 0.86 & 0.13 & 2.68
\end{tabular}

$R^{2}{ }_{c}$ coefficient of determination of calibration, $R^{2}{ }_{p}$ coefficient of determination of validation, $R M S E C$ root mean standard error of calibration, $R M S E C V$ root mean standard error of validation, $R P D$ ratio of performance to deviation

are the incidence matrices linking observations to the effects.

This model takes into account the appurtenance of the parent trees to two different groups (provenances) with the incidence matrix $Q$ which links the individuals to the ancestors (see the details of the model in Mrode and Thompson (2005).

The random effect fits a normal distribution whose parameters were:

$E\left[\begin{array}{l}a \\ e\end{array}\right]=\left[\begin{array}{l}0 \\ 0\end{array}\right]$ and $\operatorname{Var}\left[\begin{array}{l}a \\ e\end{array}\right]=\left[\begin{array}{cc}G & 0 \\ 0 & R\end{array}\right]$

The variance-covariance matrices were defined as follows:

$G=A \cdot \sigma_{A}^{2}$ and $R=I \cdot \sigma^{2}{ }_{e}$

where, $A$ is the additive genetic relationship matrix computed from a pedigree file that takes into account all the relationships between the individuals, $I$ is the identity matrix, $\sigma_{A}^{2}$ the additive genetic variance and $\sigma_{e}^{2}$ the residual variance. The variances associated with random effects were estimated by restricted maximum likelihood (REML method) using ASReml version 2 (Gilmour et al. 2005).

To compare two (or more) models, we can evaluate the Akaike Information Criteria (AIC; Akaike 1974) or the Bayesian Information Criteria (BIC; Schwarz 1978) for each model. These are given by

$\mathrm{AIC}=-2 l R_{i}+2 t_{i}$

$\mathrm{BIC}=-2 l R_{i}+t_{i} \log v$

where, $l R_{\mathrm{i}}$ is the REML log-likelihood of the model, $t_{i}$ is the number of variance parameters in model $i$ and $v$ is the residual degrees of freedom. AIC and BIC were calculated for each model and the model with the smallest value was chosen as the preferred model.
As the variances are assumed to be independent, the total phenotypic variance $\sigma_{P}^{2}$ was calculated as follows:

$\sigma_{P}^{2}=\sigma_{A}^{2}+\sigma_{E}^{2}$

The narrow-sense heritability estimates were calculated as follows:

$h^{2}=\frac{\sigma_{A}^{2}}{\sigma_{P}^{2}}$

Variances are not independent of the scale and the mean of the respective traits. Therefore, to compare the genetic and phenotypic variances of the different traits, the genetic $\left(\mathrm{CV}_{\mathrm{A}}\right)$, residual $\left(\mathrm{CV}_{\mathrm{E}}\right)$ and phenotypic $\left(\mathrm{CV}_{\mathrm{P}}\right)$ coefficient of variation were calculated as:

$\mathrm{CV}_{\mathrm{Aj}}=\frac{100 \times \sigma_{A j}}{\bar{x}}$
$\mathrm{CV}_{\mathrm{Ej}}=\frac{100 \times \sigma_{E j}}{\bar{x}}$
$\mathrm{CV}_{\mathrm{Pj}}=\frac{100 \times \sigma_{P j}}{\bar{x}}$

where, $\sigma_{\mathrm{Aj}}$ is the square root of the additive genetic variance for the trait, $\sigma_{\mathrm{Ej}}$ is the square root of the residual variance for the trait, $\sigma_{\mathrm{Pj}}$ is the square root of the phenotypic variance for the trait and $x$ is the population mean for the trait.

The estimate of phenotypic $\left(r_{P}\right)$, residual $\left(r_{E}\right)$ and genetic additive $\left(r_{A}\right)$ correlations between two traits (X and $\mathrm{Y}$ ) were performed from a bi-variate analysis using the same individual tree model as for univariate analysis. The variance-covariance matrixes $G$ and $R$ changed and were respectively the Kronecker product of a matrix related to the genetic (residual) effect (A and I) with a genetic (residual) variance-covariance matrix between the two traits ( $G t$ and $R t)$.

$G=A \otimes \mathrm{Gt} \quad \mathrm{Gt}=\left[\begin{array}{cc}\sigma_{A x}^{2} & \operatorname{Cov}_{A}(x, y) \\ \operatorname{Cov}_{A}(x, y) & \sigma_{A y}^{2}\end{array}\right]$
$G=I \otimes \mathrm{Rt} \quad \mathrm{Rt}=\left[\begin{array}{cc}\sigma_{E x}^{2} & \operatorname{Cov}_{E}(x, y) \\ \operatorname{Cov}_{E}(x, y) & \sigma_{E y}^{2}\end{array}\right]$

$r_{P}, r_{E}$ and $r_{A}$ were estimated as follows:

$r_{P}=\frac{\operatorname{Cov}_{P}(x, y)}{\sigma_{P X} \cdot \sigma P_{y}}$

$r_{E}=\frac{\operatorname{Cov}_{E}(x, y)}{\sigma_{E \cdot} \cdot \sigma_{E,}}$

$r_{A}=\frac{\operatorname{Cov}_{A}(x, y)}{\sigma_{A x} \cdot \sigma_{A y}}$

Standard errors of $h^{2}, \sigma_{A}^{2}, \sigma_{P}^{2}, r_{P}, r_{E}$ and $r_{A}$ were calculated with ASReml using a standard Taylor series approximation (Gilmour et al. 2005).

\section{Results}

The descriptive statistics of the wood traits of the 14-year $E$. urophylla are presented in Table 1. As expected for most woods, the MFA were, on average, higher near the pith 
decreasing towards the bark and an opposite trend was observed for the basic density of wood (Table 1).

The coefficients of variation were similar to those observed in previous studies on Eucalyptus in the Congo (Bouvet et al. 1999). They were higher for growth than for wood property traits in most of the cases (Table 3). Their magnitude showed that the samples used in this study could present an acceptable genetic basis to constitute a breeding population involved in genetic improvement programmes in the Republic of Congo (Bouvet et al. 2009).

\subsection{Variance components and heritability estimates}

The AIC or the BIC were calculated for each trait and showed that the model including the genetic random effect exhibited the lower AIC and BIC values and was then considered as the best model (details results not shown). This suggests that the genetic variances are significantly different from zero.

The additive genetic and residual variance components and narrow-sense heritability estimates for various traits are given in Table 3. Genetic and residual variations were higher for growth traits than for wood traits as shown by $\mathrm{CV}_{\mathrm{A}}$ and $\mathrm{CV}_{\mathrm{E}}$ (except for $\mathrm{CV}_{\mathrm{A}}$ of $\mathrm{S} / \mathrm{G}$ and $\mathrm{MFA}_{3}$ ). As expected, the narrow-sense $h^{2}$ estimates were lower for growth traits: $h^{2}=0.34$ for height and $h^{2}=0.14$ for circumference while moderate to high levels of heritability (from 0.33 to 0.76 ) were obtained for wood traits.

When the mean values of D or MFA per disc were taken into account, higher narrow-sense heritability estimates were observed $\left(h^{2}>0.60\right)$. The high magnitude of these $h^{2}$ estimates can be mathematically explained: once the three data values per tree averaged, the phenotypic (and residual) variances are sharply reduced causing an increase in the additive to phenotypic variance ratio.

Patterns in pith to cambium variation of these traits have been known for many years; wood density generally increases while MFA decreases (Kollmann and Coté 1968). The genetic control of the wood density linearly increased from 0.40 to 0.48 towards the bark; however, this linear trend should be considered with caution since the standard errors (SE) were high $(\sim 0.17)$. The $h_{\mathrm{MFA}}^{2}$ was 0.33 in the early juvenile wood $\left(\mathrm{MFA}_{1}\right)$, increasing to 0.45 in the late juvenile wood $\left(\mathrm{MFA}_{2}\right)$ and decreasing again to 0.41 in the early mature wood $\left(\mathrm{MFA}_{3}\right)$. Considering the magnitude of SE (0.105-0.155), no specific trend was observed for the heritability estimates of MFA.

\subsection{Genetic and residual correlations}

Estimates of genetic and residual correlations among growth, $\mathrm{KL}, \mathrm{S} / \mathrm{G}$ ratio and mean MFA and density are shown in Table 4. As expected, the genetic and residual correlations between growth traits were positive. The genetic correlations between growth and wood traits (MFA, D and KL) were negative. Positive residual correlations were obtained between these traits. The correlations for $\mathrm{S} / \mathrm{G}$ are low compared to their standard errors.

The strong genetic correlation between $\mathrm{C}$ and $\mathrm{D}$ was investigated by means of a residual scatter analysis (not

Table 3 Additive genetic and residual variance components, genetic and residual coefficient of variance and narrow-sense heritability estimates for circumference $(\mathrm{C})$, height $(\mathrm{H})$, Klason lignin $(\mathrm{KL})$, syringyl to guaiacyl ratio $(\mathrm{S} / \mathrm{G})$, wood density $(\mathrm{D})$, and microfibril angle (MFA)

\begin{tabular}{|c|c|c|c|c|c|c|c|c|}
\hline \multirow[t]{2}{*}{ Trait } & \multicolumn{3}{|c|}{ Additive genetic variance } & \multicolumn{3}{|c|}{ Residual variance } & \multicolumn{2}{|c|}{ Genetic control } \\
\hline & $\sigma_{A}^{2}$ & $\operatorname{SE} \sigma_{A}^{2}$ & $\mathrm{CV}_{A}$ & $\sigma_{E}^{2}$ & $\mathrm{SE} \sigma_{E}^{2}$ & $\mathrm{CV}_{E}$ & $h^{2}$ & SE $h^{2}$ \\
\hline $\mathrm{C}$ & 13.70 & 9.95 & 7.0 & 100.10 & 9.12 & 19.0 & 0.14 & 0.087 \\
\hline $\mathrm{H}$ & 3.752 & 1.896 & 9.2 & 11.089 & 1.180 & 15.7 & 0.34 & 0.136 \\
\hline KL & 1.206 & 0.529 & 3.9 & 1.584 & 0.276 & 4.5 & 0.76 & 0.212 \\
\hline SG & 0.067 & 0.030 & 11.3 & 0.095 & 0.016 & 13.4 & 0.71 & 0.208 \\
\hline $\mathrm{D}_{1}$ & 8.796 & 4.525 & 6.7 & 22.226 & 2.685 & 10.6 & 0.40 & 0.167 \\
\hline $\mathrm{D}_{2}$ & 8.330 & 4.153 & 5.5 & 20.055 & 2.454 & 8.6 & 0.42 & 0.168 \\
\hline $\mathrm{D}_{3}$ & 12.384 & 5.948 & 5.7 & 25.657 & 3.379 & 8.2 & 0.48 & 0.180 \\
\hline $\mathrm{D}$ & 9.139 & 3.914 & 5.7 & 14.931 & 2.184 & 7.3 & 0.61 & 0.183 \\
\hline $\mathrm{MFA}_{1}$ & 1.082 & 0.478 & 5.8 & 3.188 & 0.299 & 9.9 & 0.33 & 0.105 \\
\hline $\mathrm{MFA}_{2}$ & 1.630 & 0.770 & 8.3 & 3.643 & 0.406 & 12.4 & 0.45 & 0.139 \\
\hline $\mathrm{MFA}_{3}$ & 1.557 & 0.625 & 9.4 & 3.539 & 0.387 & 14.1 & 0.41 & 0.155 \\
\hline MFA & 1.105 & 0.544 & 6.8 & 2.643 & 0.311 & 10.4 & 0.43 & 0.153 \\
\hline
\end{tabular}

For D and MFA, the index correspond to radial position, 1 is close the pith. The phenotypic values of wood density were divided by 10 for estimating its variance components

$\sigma_{A}^{2}$ additive genetic variance component, $\sigma_{E}^{2}$ residual variance component, $h$ - narrow-sense heritability estimates, $S E$ standard errors 
Table 4 Estimated additive genetic $\left(r_{A}\right.$, below the diagonal) and residual $\left(\mathrm{r}_{\mathrm{E}}\right.$, above the diagonal) correlations for circumference $(\mathrm{C})$, height $(\mathrm{H})$, microfibril angle (MFA), wood density (D), Klason lignin (KL), and syringyl to guaiacyl ratio $(\mathrm{S} / \mathrm{G})$

Standard errors are shown in parentheses

\begin{tabular}{lrllllr}
\hline & C & H & MFA & \multicolumn{1}{l}{ D } & \multicolumn{1}{l}{ KL } & \multicolumn{1}{l}{ S/G } \\
\hline C & & $0.80(0.05)$ & $0.01(0.12)$ & $0.45(0.21)$ & $0.33(0.21)$ & $-0.17(0.17)$ \\
H & $0.47(0.33)$ & & $0.16(0.19)$ & $0.41(0.24)$ & $0.40(0.37)$ & $-0.41(0.28)$ \\
MFA & $-0.36(0.38)$ & $-0.83(0.17)$ & & $-0.68(0.28)$ & $0.16(0.32)$ & $0.38(0.32)$ \\
D & $-0.94(0.21)$ & $-0.55(0.27)$ & $0.54(0.27)$ & & $-0.35(0.44)$ & $0.03(0.39)$ \\
KL & $-0.16(0.40)$ & $-0.60(0.25)$ & $0.70(0.17)$ & $0.28(0.28)$ & & $-0.23(0.43)$ \\
S/G & $0.08(0.41)$ & $0.35(0.31)$ & $-0.11(0.31)$ & $-0.61(0.21)$ & $-0.17(0.30)$ & \\
\hline
\end{tabular}

shown). The point dispersions revealed that there was no aberrant point, which could strengthen the correlation. The correlation estimates had large standard errors probably due to the small sample size.

Radial variations of genetic, residual and phenotypic correlations between wood and growth traits are presented in Fig. 2. The genetic correlation between circumference and wood density remained high during all phases of wood formation, while that between circumference and MFA seemed to linearly decrease towards the bark. This trend was also found between MFA and lignin in which there was an increase with age. The genetic correlation between MFA and wood density decreased from juvenile to mature wood.

The residual correlations were low, except for that between MFA and D. The phenotypic and additive genetic correlations between $\mathrm{C}$ and MFA, and KL and MFA presented the same trends, with slight differences in their magnitude. The phenotypic correlation between circumference and wood density was null while the genetic correlation was strong. Similarly, the phenotypic correlation between $\mathrm{MFA} \times \mathrm{D}$ was low while the residual and genetic correlations were high.

In general, additive genetic correlations presented higher magnitudes when compared with the residual correlations. Moreover, the radial variations of the values of the genetic relationships were stronger than those for residual or phenotypic correlations.

\section{Discussion}

This study compares the genetic control of wood and growth traits, with special focus on microfibril angle which has been poorly reported in hardwood species. Moreover, genetic and environmental correlations among these traits were assessed at different ages, thus improving our knowledge on the functional aspects of wood formation in E. urophylla.

\subsection{Heritability of MFA and wood traits}

Moderate $h^{2}$ estimates were obtained for MFA $\left(h^{2}=0.43 \pm\right.$ 0.15 ) when calculated from the mean values per disc (Table 3 ). These narrow-sense heritabilities were higher than those reported in two previous studies. Apiolaza et al. (2005) used increment cores from 188 open-pollinated progenies of 11-year-old E. globulus and obtained $h_{\mathrm{MFA}}{ }^{2}=0.27 \pm 0.24$. These relatively lower narrow-sense $h^{2}$ estimates of Apiolaza et al. (2005) can be attributed to (1) larger environmental variation since their $\mathrm{CV}_{\mathrm{A}}(8.36 \%)$ is close to the average $\mathrm{CV}_{\mathrm{A}}$ of Table 3 (8\%); (2) use of a larger number of provenances and (3) fitting provenances as a fixed effect in the model. Lima et al. (2004) reported $H^{2}$ of 0.29 in 8-year-old Eucalyptus wood. Normally, broad-sense heritability estimates are higher than narrow-sense estimates. The low $H^{2}$ estimate of Lima et al. (2004) was expected since they evaluated selected clones of $E$. grandis $\times E$. urophylla for pulpwood so the genetic base was narrow.

Just as for the phenotypic values, the genetic control also varied with age. The heritability estimates of the MFA in the early juvenile wood $\left(h_{\mathrm{MFA} 1}{ }^{2}=0.33 \pm 0.105\right)$ increased towards the late juvenile wood $\left(h_{\mathrm{MFA} 2}{ }^{2}=0.45 \pm 0.139\right)$, decreasing in the early mature wood $\left(h_{\mathrm{MFA} 3}{ }^{2}=0.41 \pm 0.155\right)$. However, due to the high standard error, no specific trend can be demonstrated. This result was similar to the variation pattern reported by Lima et al. (2004) in Eucalyptus clones ( $h_{\mathrm{MFA}}{ }^{2}$ increasing from 0.13 to 0.36 and then decreasing to 0.16 towards the cambium). Comparing these findings requires prudence because the experimental designs were different (open- and control-pollinated and clonally propagated tests) and the methods of wood phenotyping were distinct: Apiolaza et al. (2005) estimated the phenotypic MFA values of their study by means of the SilviScan device (based on X-ray diffraction, see Evans 1999); Lima et al. (2004) used polarised light microscopy technique and, here, we associated X-ray-diffraction and NIR spectroscopy to estimate the MFA.

Considerable genetic control was found for mean wood density $\left(h^{2}=0.61 \pm 0.183\right)$ and for wood density measurements at different radial positions. The heritability estimates linearly increased from the early juvenile wood $(0.40 \pm$ $0.167)$ towards the early mature wood $(0.48 \pm 0.180)$. The slight increment in heritability estimates of density with age might have been due a reduction in environmental variation, which may have been associated with canopy closure in the Congolese conditions. Previous studies on Eucalyptus in the environmental conditions of the Congo have shown that 
Fig. 2 Variation with age of phenotypic, residual and additive genetic correlations of density (D) with circumference (C), and microfibril angle (MFA) with C, Klason lignin (KL) and $\mathrm{D}$ and representation of standard error of estimation
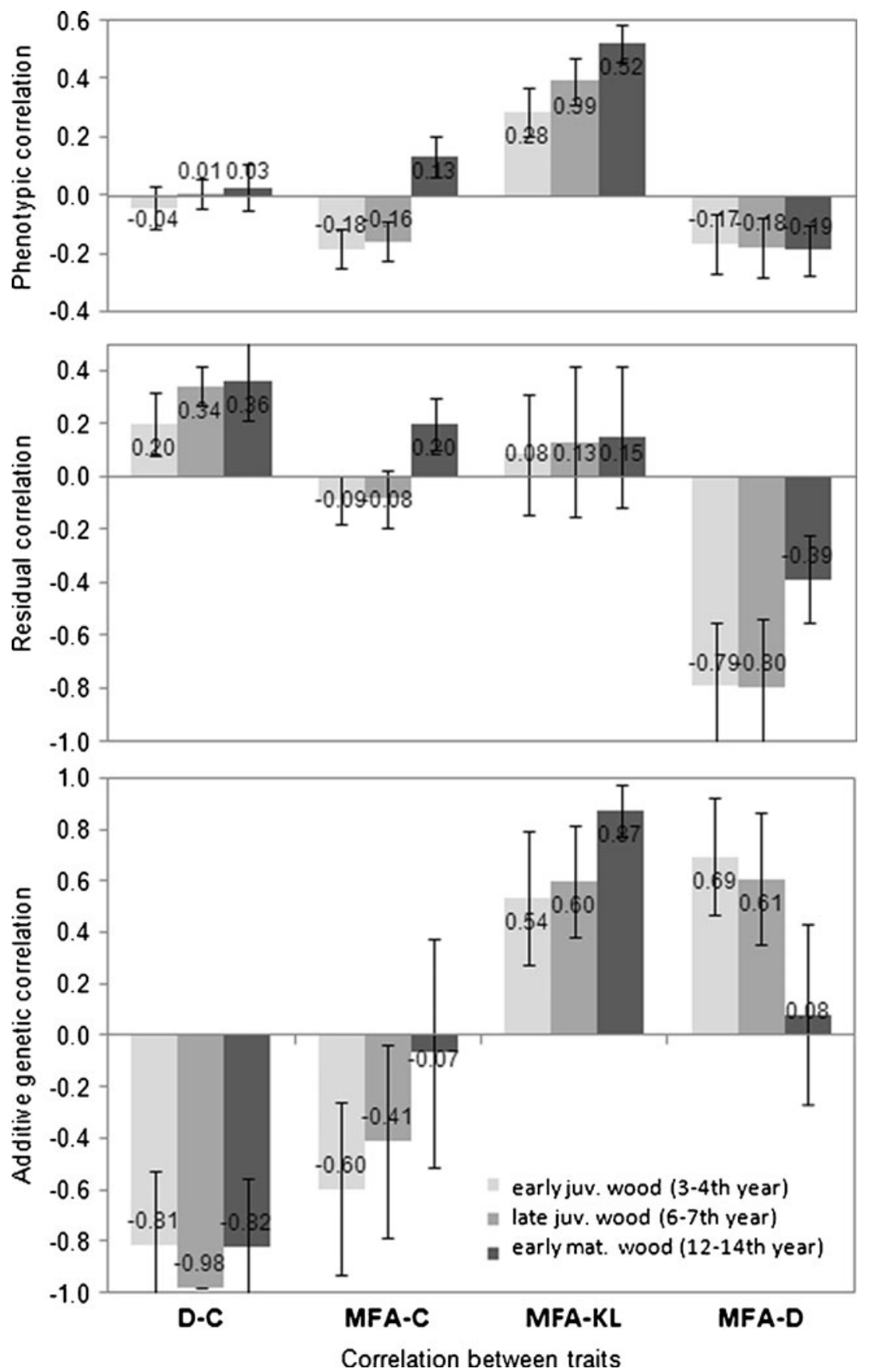

before canopy closure, there are large micro-environmental variations between trees while in the following years, tree development depends to a higher magnitude on their genetic potential (Bouvet et al. 2003). Due its relatively easy and simple measurement, the wood density has been extensively investigated in Eucalyptus and the heritability of such trait exhibits variable magnitudes: from $H^{2}=0.51 \pm 0.13$ (Kube et al. 2001, for all sites) to $h^{2}=0.73$ (Greaves et al. 1997, for whole-disc density at $1.3 \mathrm{~m}$ across sites) in E. nitens; from $h^{2}=$ $0.24 \pm 0.26$ (Poke et al. 2006) to $h^{2}=0.44 \pm 0.22$ (Apiolaza et al. 2005) in E. globulus and from $h^{2}=0.17 \pm 0.12$ (Raymond et al. 1998) in E. regnans. Most of these studies have shown that the high heritability of this trait is mainly explained by the low environmental influence rather than marked genetic variation (see CV's in Table 3); our study reinforces these previous results.

Lignin content and $\mathrm{S} / \mathrm{G}$ ratio were shown to be under strong genetic control (Table 3). The high narrow-sense heritability of these chemical traits $\left(h^{2}>0.70 \pm 0.2\right)$ indicates that genetic gain is possible through breeding. The heritability for lignin $\left(h^{2}=0.76 \pm 0.212\right)$ was lower than that reported by Gominho et al. (1997) in E. globulus clones 
$\left(h^{2}=0.83\right)$ but higher than that reported by Vigneron et al. (2004) in E. urophylla $\times$ grandis (individual broad-sense $H^{2}=0.27 \pm 0.2$ ), Poke et al. (2006) in E. globulus families (narrow-sense $h^{2}=0.13 \pm 0.2$ and family means $h^{2}=0.42 \pm$ $0.19)$. As lignin content and its composition are key traits of Eucalyptus-breeding programmes, especially for pulp, paper and bioenergy production, their high genetic control reported here (Table 3) is important for tree breeders. For instance, high lignin content is desirable for bio-energy because lignin has a high calorific value.

The heritability estimates for growth traits were low $\left(h^{2}=\right.$ $0.14 \pm 0.087 ; h^{2}=0.34 \pm 0.136$ for circumference and height, respectively), which are strongly influenced by the environment. These results confirm the trends described in previous studies for other Eucalyptus-breeding programmes (Kube et al. 2001; Costa e Silva et al. 2009, 2010) and more specifically in the Congo (Bouvet et al. 2003, 2009). Similar studies on conifers have also reported that growth properties are under less genetic control than wood properties (Zubizarreta Gerendiain et al. 2007).

Although these estimates are population- and site-specific, these findings are coherent with previous studies and useful for tree breeders since they show that MFA, D, KL and S/G present a high heritability and offer possibilities for improvement.

\subsection{Correlation at mature age}

A lot of literature exists about genetic correlations between growth traits and wood density; however, the findings concerning this issue are inconsistent (see for example Zobel and Van Buijtenen (1989) for a range of wood species). For Eucalyptus, several studies also show inconsistent results (Hamilton and Potts 2008; Greaves et al. 1997; Wei and Borralho 1999; Kube et al. 2001) probably due to the small sampling size. The conclusion is that correlation between wood density and growth should be low. In addition, some studies have shown that correlations are influenced by site conditions (Wei and Borralho 1999; Muneri and Raymond 2000; Hamilton et al. 2009) emphasising the environmental impact.

Our results bring new elements to the understanding of the correlation between wood and growth traits. Here, few additive and residual correlations $(\mathrm{C} \times \mathrm{H} ; \mathrm{KL} \times \mathrm{MFA})$ presented the same sign (Table 4 and Fig. 2). This could indicate a pleiotropic gene effect (Falconer 1993), suggesting that these two traits are governed by a given genetic locus (Mode and Robinson 1959).

Most of the additive and residual correlations, and especially those related to MFA (Table 4) had negative sign. This indicates that linkage disequilibrium (non-random associations of genes) between loci may affect the relationship among different wood traits (Falconer 1993). This means that the genes controlling these traits can be statistically associated, but there is no functional relationship among them. Sampling procedure adopted in this study could have played a role in linkage disequilibrium, since the trees were selected among the best ones with respect to growth and stem straightness. According to Villanueva and Kennedy (1990), selection changes the genetic variance and creates linkage disequilibrium.

\subsection{Genetic parameter expression with age}

As the tree grows upward, new layers of wood are produced and overlapped in order to withstand the ever-increasing mass of the tree. The variations of the genetic and residual correlations with age may be useful in understanding how the cambial activity and maturation phases are regulated in order to modify the characteristics of the wood making the stem able to withstand gravity and bending movements caused by winds.

The narrow-sense heritability estimates for wood density seems to increase with age (Table 3), but remains more or less constant for MFA. The variances were heterogeneous across ages: the variance of wood density increased with age (trees become more different) while the variance of MFA presented no trends (Table 3 ). The genetic correlation $\mathrm{C} \times \mathrm{D}$ is always strongly negative while the correlation $\mathrm{D} \times \mathrm{MFA}$ remained constant in the juvenile wood, decreasing considerably in the mature wood (Fig. 2). This could mean that trees with a strong potential to grow fast are genetically programmed to produce low-density woods and also to decrease the microfibril angles to help ensure stiffness (the negative correlation MFA $\times$ C). However, the sample size (340 trees) is quite small and any genetic correlations were estimated to have large associated errors. Furthermore, the eventual occurrence of linkage disequilibrium within this population means that a functional explanation needs to be treated with caution.

Eucalyptus trees can reach $25-30 \mathrm{~m}$ of height in 67 years. As the tree grows, enlarging its diameter and increasing its height, the stem becomes more subject to higher bending moments from the wind. It is known that reaction wood is typically formed as the tissues of the periphery are held in "tension" and in many wood species, tension wood is characterised by the presence of a thick and unlignified, inner cell-wall layer that consists of highly crystalline cellulose, in which the MFA is close to zero (Kollmann and Coté 1968). Thus, the low lignin content and MFA of the early mature wood may be associated with tension wood occurrence (Fig. 2). Our results indicate that variations in these wood traits are also genetically controlled since the genetic correlation between MFA and KL increases from 0.54 to 0.87 towards the cambium.

\subsection{Implications for selection}

These findings bring additional insights for genetic breeding strategies. If the population analysed in this study is to 
constitute the first generation of a breeding programme, different elements should be taken into account for selecting candidate trees.

For the purposes of pulpwood production, the objective is to produce trees with high biomass value (volume, density and cellulose content) and reduced lignin content. The negative $r_{A}$ between growth traits and lignin content $\left(r_{A}=-0.60\right.$ for height and -0.16 for circumference) and the positive correlation between MFA and $\mathrm{KL}\left(0.54<r_{A}<0.87\right)$ are favourable for pulp and paper production since the reduction in all of these traits should be simultaneously possible. Lignin is an undesirable compound for pulp and paper production, because the delignification process requires energy and reagent consumption

For bio-energy production, the positive genetic correlation between lignin and density $(0.28)$ is favourable, despite the low magnitude. However, positive additive correlations between MFA and lignin are unfavourable for bioenergy purposes since decreasing MFA, may result in decreasing lignin content. The problem is that, for energy production, the wood must simultaneously have high lignin content and adequate mechanical properties. Charcoal is used in blast furnaces for iron-steel production and has to support the weight of the iron feedstock during the steps of oxidation-reduction reactions at elevated temperatures (above $1,500^{\circ} \mathrm{C}$ ) without breaking.

For sawn wood production, the objective is to obtain stiff (low MFA), dense and dimensionally stable wood from trees with low growth stresses. Our findings have shown that wood density and MFA were genetically unfavourably correlated with growth. Moreover, selection for increasing density will result in an increase of MFA and decrease of wood stiffness, the major wood trait for structural, furniture and flooring uses.

As pointed out by Baltunis et al. (2007), breeders, forest managers and wood producers will have to strike a balance between overall wood and growth traits, and geneticists should develop breeding strategies to deal with such negative, unfavourable genetic correlations. For Eucalyptus, developing breeding objectives may be the first step in dealing with these unfavourable genetic correlations between wood and growth traits.

Acknowledgements The authors would like to thank Arie van der Lee from the Institut Européen des Membranes for assistance with X-ray diffraction measurements; Dr. C Lapierre and her work team from INRA-Agro ParisTech for chemical analysis; N Ognouabi and E Villar from CRDPI (Republic of Congo) and the "Bureau des Ressources Génétiques" (BRG) project for providing material and funding; and especially Dr. JM Gion (coordinator of the BRG project "CCR gene in Eucalyptus: a model of functional variability in forest trees") from CIRAD for providing technical support.

Funding This study is a part of the project "CCR gene in Eucalyptus: a model of functional variability in forest trees" funded by the "Bureau des Ressources Génétiques" (BRG). The project was also funded by the Centre de Coopération Internationale en Recherche Agronomique pour le Development (CIRAD) in Montpellier, France. The first author was supported by the National Council of Technological and Scientific
Development (CNPq, Brazil-process no. 200970/2008-9) during his $\mathrm{PhD}$ thesis. He was also supported by the Alfa Gema Project (II-0266FA) during his masteral studies.

\section{References}

Akaike H (1974) A new look at the statistical model identification. IEEE Trans Autom Control 19:716-723

Apiolaza LA (2009) Very early selection for solid wood quality: screening for early winners. Ann For Sci 66:601

Apiolaza LA, Raymond CA, Yeo BJ (2005) Genetic variation of physical and chemical wood properties of Eucalyptus globulus. Silvae Genet 54:4-5

Baltunis BS, Wu HX, Powell MB (2007) Inheritance of density, microfibril angle, and modulus of elasticity in juvenile wood of Pinus radiata at two locations in Australia. Can J For Res 37:2164-2174

Bouvet JM, Bouillet JP, Vigneron P, Ognouabi N (1999) Genetic and environmental effects on growth and wood basic density with two Eucalyptus hybrids. In: 09/99 Connexion between silviculture and wood quality through modelling approaches and simulation softwares: modelling approaches and simulation softwares. La Londe-Les Maures, France, September, 5-12

Bouvet JM, Vigneron P, Gouma R, Saya A (2003) Trends in variances and heritabilities with age for growth traits in Eucalyptus spacing experiments. Silvae Genet 52:3-4

Bouvet JM, Saya A, Vigneron P (2009) Trends in additive, dominance and environmental effects with age for growth traits in Eucalyptus hybrid populations. Euphytica 165:35-54

Costa e Silva J, Borralho NMG, Araujo JA, Vaillancourt RE, Potts BM (2009) Genetic parameters for growth, wood density and pulp yield in Eucalyptus globulus. Tree Gen Genom 5:291-305

Costa e Silva J, Hardner C, Potts BM (2010) Genetic variation and parental performance under inbreeding for growth in Eucalyptus globulus. Ann For Sci. doi:10.1051/forest/2010019

Evans R (1999) A variance approach to the X-ray diffractometric estimation of microfibril angle in wood. Appita J 52:283-289

Evans R, Ilic J (2001) Rapid prediction of wood stiffness from microfibril angle and density. For Prod J 51:53-57

Falconer DS (1993) Introduction to quantitative genetics. Longman, New York

Gilmour AR, Gogel BJ, Cullis BR, Welham SJ, Thompson R (2005) ASReml user guide release 2.0, VSN international Ltd, Hemel Hempstead HP1 1ES, UK

Gominho J, Rodrigues J, Almeida MH, Leal A, Cotterill PP, Pereira H (1997) Assessment of pulp yield and lignin content in a firstgeneration clonal testing of Eucalyptus globulus in Portugal, in: Proceedings of the IUFRO Conference on Silviculture and Improvement of Eucalypts, Salvador, Brazil, August 24-29, 1997, p. 84-89

Greaves BL, Borralho NMG, Raymond CA, Evans R, Whiteman PH (1997) Age-age correlations and relationships between basic density and growth in Eucalyptus nitens. Silvae Genet 46:264-270

Hamilton MG, Potts BM (2008) Eucalyptus nitens genetic parameters. N Z J For Sci 38:102-119

Hamilton MG, Raymond CA, Harwood E, Potts BM (2009) Genetic variation in Eucalyptus nitens pulpwood and wood shrinkage traits. Tree Gen Genom 5:307-316

Hein PRG, Lima JT, Chaix G (2009) Robustness of models based on near infrared spectra to predict the basic density in Eucalyptus urophylla wood. J Near Infrared Spec 17:141-150

Hein PRG, Lima JT, Chaix G (2010a) Effects of sample preparation on NIR spectroscopic estimation of chemical properties of Eucalyptus urophylla S.T. Blake wood. Holzforschung 64:45-54 
Hein PRG, Clair B, Brancheriau L, Chaix G (2010b) Predicting microfibril angle in Eucalyptus wood from different wood faces and surface qualities using near infrared spectra. J Near Infrared Spec 18:455-464

Kollmann FR, Coté WA (1968) Principles of wood science and technology. Springer, Berlin

Kube PD, Raymond CA, Banham PW (2001) Genetic parameters for diameter, basic density, cellulose content and fibre properties for Eucalyptus nitens. For Gen 8:285-294

Lima JT, Breese MC, Cahalan CM (2004) Variation in microfibril angle in Eucalyptus clones. Holzforschung 58:160-166

Mode CJ, Robinson HF (1959) Pleiotropism and the genetic variance and covariance. Biometrics 15:518-537

Mrode RA, Thompson R (2005) Linear models for the prediction of animal breeding values, 2 nd edn. CABI, Cambridge, MA

Muneri A, Raymond CA (2000) Genetic parameters and genotypeby-environment interactions for basic density, pilodyn penetration and stem diameter in Eucalyptus globulus. For Gen 7:317-328

Poke FS, Potts BM, Vaillancourt RE, Raymond CA (2006) Genetic parameters for lignin, extractives and decay in Eucalyptus globulus. Ann For Sci 63:813-821

Raymond CA (2002) Genetics of Eucalyptus wood properties. Ann For Sci 59:525-531
Raymond CA, MacDonald AC (1998) Where to shoot your pilodyn: within tree variation in basic density in plantation Eucalyptus globulus and E. nitens in Tasmania. New For 15:205-221

Raymond CA, Banham P, MacDonald AC (1998) Within tree variation and genetic control of basic density, fibre length and coarseness in Eucalyptus regnans in Tasmania. Appita J 41:299-305

Schwarz GE (1978) Estimating the dimension of a model. Ann Stat 6:461-464

Vigneron P, Giordanengo T, Ognouabi N, Gion JM, Chaix G, Baillères H (2004) Genetic components of wood quality traits in Eucalyptus urophylla $\times E$. grandis full sib families. IUFRO Congress unit 2.08.03 "Eucalyptus in a Changing World", Aveiro, Portugal, October, 11-15

Villanueva B, Kennedy BW (1990) Effect of selection on genetic parameters of correlated traits. Theor Appl Gen 80:746-752

Wei X, Borralho NMG (1999) Objectives and selection criteria for pulp production of Eucalyptus urophylla plantation in south east China. For Gen 6:181-190

Zobel BJ, Van Buijtenen JP (1989) Wood variation - its causes and control. Springer, Berlin

Zubizarreta Gerendiain A, Peltola H, Pulkkinen P, Jaatinen R, Pappinen A, Kellomäki S (2007) Differences in growth and wood property traits in cloned Norway spruce (Picea abies). Can J For Res 37:2600-2611 